\title{
More whistleblowing cases reported to GDC than any other health regulator
}

The dental regulator received more whistleblowing cases from workers in 2017-18 than any of the eight healthcare regulators, according to a newly published report.

The Whistleblowing disclosures report $2018^{1}$ was published jointly by the various regulators on 11 September 2018.

It details cases from the GDC, General Medical Council (GMC), Nursing \& Midwifery Council (NMC), General Chiropractic Council, General Optical Council, General Osteopathic Council, General Pharmaceutical Council, and Health \& Care Professions Council.

Since April 2017, a new legal duty came into force which required all prescribed bodies to publish an annual report on the whistleblowing disclosures made to them by workers and the new joint report highlights the regulators' coordinated effort to work together in handling serious issues.

It shows that between 1 April 2017 and 31 March 2018, the GDC received 61 whistleblowing disclosures - more than the 60 such cases received by the Nursing and Midwifery Council (which regulates around six times more professionals than the GDC) - and almost three times the number received by fellow regulator the GMC, which accumulated 23 cases.

Of the GDC's 61 disclosures, 47 led to regulatory action, seven were closed with no action taken, four resulted in no action being taken due to not enough information, and three were referred onwards.

The majority of disclosures (51) were made direct to the GDC's Fitness to

Practise (FtP) team. In addition, two disclosures were made during this period relating to education providers.

One disclosure related to a course provider where the GDC was already undertaking regulatory action. The second disclosure resulted in a number of FtP cases relating to clinical concerns being opened and investigated.

A further three of the disclosures were received by the GDC's illegal practice team. A criminal prosecution can be brought by the GDC if there is sufficient evidence for there to be a realistic prospect of conviction and if so, it is in the public interest to pursue the matter to a prosecution.

'Cease and desist' letters, requiring the illegal practice to be discontinued, were sent in response to all three of these disclosures.

In comparison, the nursing and midwifery regulator the NMC received 60 official whistleblowing cases despite covering a much larger register of more than 690,000 professionals - compared to the 111,000 professionals on the GDC's register.
Of the NMC's 60 cases, 53 led to regulatory action being taken most often in the form of being dealt with by its Fitness to Practise directorate - and seven were referred onwards to an alternative body (such as the Care Quality Commission) and regulatory action taken.

Doctors' regulator the GMC only received 23 whistleblowing disclosures despite having a register of around 298,000 professionals.

With the GMC's cases, regulatory action was taken in 21 cases and no action was taken for the other two. All of the whistleblowing disclosures received came to its Fitness to Practise directorate.

In the report, a GDC spokesperson acknowledged the higher number of whistleblowers compared with many of the other regulators and said this could be due to how dental care was provided.

'The absolute number of disclosures we have received has been too small to discern emerging trends. Compared to some other regulators we have received a higher number of disclosures in comparison to the size of the register,' said the spokesperson.

'While we are unable to form firm conclusions as to why this might be the case, it is worth noting that most dentistry is provided in a primary care setting and out with the more robust clinical governance frameworks that characterise some other forms of healthcare.

'This may mean that alternative disclosure routes are less present in dentistry, and a larger proportion are dealt with by the regulator. We may be able to explore this further as we collect more data.

'In the vast majority of cases, the action we would take in response to a disclosure does not differ from the regulatory action we would normally take.' The other regulators received far fewer whistleblowing disclosures in 2017-18 with the General Chiropractic Council not receiving any.

Anna Rowland, Assistant Director of Policy, Business Transformation and Safeguarding at the GMC, said: 'We want whistleblowers to feel confident in raising their concerns to us and so we have improved the process by which disclosures can be made, giving people the option to do so anonymously.

'The collaboration with seven health regulators has demonstrated that we all take disclosures from whistleblowers seriously and we all take a consistent approach. Working together should give people confidence that action will be taken where necessary'.

1. Whistleblowing disclosures report 2018 (11 September 2018). Available online at https://www.gmc-uk.org/-/media/documents/whistleblowing-report-2018_pdf75910452.pdf (accessed 18 September 2018). 